\title{
Management of Papanicolaou test results that lack endocervical cells
}

\author{
Lizette Elumir-Tanner MD, Meghan Doraty BHSc; for the Southern Alberta Primary Care Research \\ Network (SAPCReN)
}

\section{The case}

Mrs. McTavish is a 25-year old patient whose Papanicolaou (Pap) test results have come back from the laboratory. The smear is described as satisfactory for evaluation; however, it is noted that an inadequate number of endocervical cells were present in the sample. The results of the patient's past Pap tests have been satisfactory for evaluation and negative for abnormality. She is otherwise well. Her physical examination, including pelvic examination, showed nothing unusual.

$\mathrm{R}$ ates of cervical cancer have been declining in Canada since the implementation of the Papanicolaou (Pap) smear, with reduction in both incidence (from 11.1 per 100000 in $1970-1972$ to 5.2 per 100000 in 1994-1996) and mortality (7.9 per 100000 in $1953-1955$ to 1.9 per 100000 in 1995-1997). ${ }^{1}$ Further improvements will depend on the continuance of screening for cervical cancer and the effectiveness of screening tools. The Bethesda System - the conventional system for reporting cervical cytologic diagnoses - provides feedback about specimen adequacy using the categories "satisfactory" or "unsatisfactory." Primary health care providers may receive Pap test results that are identified as satisfactory but accompanied by a note that indicates a sample from the transformation zone is lacking. Some provincial and national guidelines are unclear about how clinicians should respond to this type of report. Because of this uncertainty, we sought to review the current evidence on the topic. How should a care provider proceed with screening when faced with an otherwise satisfactory Pap smear that lacks sampling from the transformation zone? If physicians continue with regular screening intervals without special attention to the lack of endocervical cells, are cervical abnormalities being missed?

\section{Literature review}

We searched MEDLINE from 1975 to the end of July 2010 using the following combination of keywords and subject headings: "unsatisfactory Pap smear," "endocervical component," "endocervical status," "endocervical cells and Pap smear," "Pap smear and quality" and "abnormal Pap smear." Bibliographies from the identified articles were manually searched. Summary sites such as Towards Optimal Practice (Alberta) and Cancer Care Manitoba were also reviewed in July 2010. We identified 462 citations, and reviewed 53 full-text articles. Papers were excluded if they were written in a language other than English, if they did not discuss the topic of Pap smear quality and presence or absence of endocervical cells, and if there were insufficient data to draw conclusions. Twenty-four articles were included in our review and are summarized in Appendix 1 (available at www.cmaj.ca/cgi/content/full/cmaj.101156/DC1).

The level of evidence was determined by the hierarchy developed by the Canadian Task Force on the Periodic Health Examination, ${ }^{3}$ according to which the highest level of evidence (Level I) derives from at least one randomized controlled trial, and the lowest level derives from the opinion of experts (Level III). The evidence identified in our search was predominantly Level II, indicating that the literature contained mainly cohort, cross-sectional and case-control studies. No randomized controlled trials, systematic reviews or meta-analyses were found.
Competing interests: None declared.

This article has been peer reviewed.

Correspondence to: Meghan Doraty, medoraty@ucalgary.ca

CMAJ 2011. DOI:10.1503 /cmaj.101156 


\section{What is an adequate sample?}

The effectiveness of screening using the Pap smear relies on adequate sampling from the cervix. ${ }^{1}$ Although a conclusive definition of "adequate sample" remains elusive, the retrieval of endocervical cells from an area of the cervix known as the transformation zone or squamocolumnar junction, from which most abnormalities arise, ${ }^{4}$ has historically been considered an indication of quality. ${ }^{5}$ Some older studies ${ }^{5-14}$ have shown a relationship between the presence of endocervical cells and the identification of cervical abnormality. Such findings are consistent with the hypothesis that samples with endocervical cells are more likely to detect atypia. However, more recent research ${ }^{15-28}$ has shown that the absence of endocervical cells is not necessarily associated with a higher risk of cervical abnormality.

\section{What do the guidelines recommend?}

Not all provinces and territories in Canada have guidelines for screening for cervical cancer or a screening program (Table 1). Of those that do, ${ }^{29-35}$ most do not definitively address how to respond to a Pap smear result when it lacks a sample from the transformation zone. Guidelines in Nova Scotia ${ }^{34}$ and in Manitoba ${ }^{32}$ suggest early repeat testing may not be necessary. The recently revised guidelines in Alberta ${ }^{29}$ note that the sample may still be satisfactory if endocervical cells are missing.

International guidelines vary. Recent guidelines from the United Kingdom ${ }^{36}$ recommend testing every three years for women aged 25 to 49 years, but make no mention of what to do should results not include endocervical cells. Australian guidelines ${ }^{37}$ which recommend screening every two years, cite retrospective cohort studies and note that the quality of a smear is not determined by the presence or absence of endocervical cells. The American Cancer Society ${ }^{38}$ recommends annual repeat screening for women whose Pap smears show no endocervical cells, or earlier repeat testing for certain women. These guidelines do not clarify which women qualify for early repeat testing; this ambiguity may cause confusion for physicians about who and when to retest.

\section{What is the evidence?}

The debate regarding the significance of endocervical cells was sparked when initial research found that the presence of endocervical cells on a smear was related to an increase in detection of abnormalities of the cervix..$^{5-10,12,13}$ One study ${ }^{8}$ assessing the cytologic histories of 376 women diagnosed with invasive carcinoma of the cervix found that endocervical cells were seen less often in smears reported as negative $(45.5 \%)$ than in those with atypia (84.4\%) and those with cervical intraepithelial neoplasia (97.8\%). This difference was significant $(p<0.001)$, suggesting that the composition of the smear was related to the detection of abnormalities. To best identify atypia, the authors argued, a repeat test is necessary.

Further studies verified this finding. Another study $^{10}$ reviewed 36853 Pap smears to investigate the effect of the presence or absence of endocervical cells on the detection rate of abnormalities, with the result that cervical intraepithelial neoplasia (CIN) was detected 2.3 times more often in smears with endocervical cells. Two further studies reviewed false-negative Pap smears from patients who had a confirmed diagnosis of cervical cancer. Many of these smears (35 of 94 [37\% $]^{12}$ and 30 of $47[64 \%]^{13}$ ) were missing endocervical cells. Based on this evidence, it became standard practice for physicians to sample endocervical cells to improve the chances that abnormalities were caught and to test repeatedly as deemed necessary when endocervical cells were not present.

However, recent retrospective studies ${ }^{15,21,23,24}$ assessed the effect of the presence or absence of endocervical cells on the rate of detection of abnormalities by comparing the concordance between cytology (assessed by Pap smear) and histology (assessed by colposcopic examination). One study ${ }^{23}$ examined 151 instances of histologically diagnosed CIN II and III and retrieved the Pap tests to determine discordant, or false-negative, cases. Of the 13 Pap tests lacking an endocervical component, only $3(23 \%)$ were discordant, whereas of the 138 Pap tests with an endocervical component, 38 (27\%) were discordant. There was no significant difference between these groups $(p>0.5)$, suggesting that the inclusion of an endocervical component within a smear does not guarantee that an existing abnormality will be detected. Other casecontrol studies ${ }^{17,18,20,25}$ support this finding. Thus an endocervical component may not be a good indicator of specimen quality, and its lack may not indicate that early repeat testing is necessary.

The most convincing evidence, however, is found in longitudinal studies in which patients were prospectively evaluated for the presence of endocervical cells and for subsequent abnormal Pap smears. ${ }^{16,22,26,27}$ Methods of reporting cervical atypia have changed over the years, so among these studies, the measured outcome varied (i.e., CIN v. low-grade squamous intraepithelial lesion v. atypia). As well, the length of follow-up dif- 
fered among studies. However, the essence of the findings was consistent: women whose Pap smears did not contain endocervical cells were not at higher risk for subsequent detection of cervical abnormalities than those whose smears did contain endocervical cells.

Perhaps the most convincing longitudinal study was performed by Mitchell in 2001.22 Four cohorts of women who had an initial negative Pap smear and a subsequent Pap smear three years later were studied. Endocervical cells were present in both entry and exit smears in cohort $\mathrm{A}(n=$ 18 618); endocervical cells were absent in the entry smear and present in the exit smear in cohort $\mathrm{B}(n=16632)$; endocervical cells were present in the entry smear and absent in the exit smear in cohort C $(n=16291)$; and both smears had absent endocervical cells in cohort D $(n=8603)$. One would expect a higher incidence of disease in cohort B compared with cohort A, given that cohort B would be more likely to exhibit missed abnormalities in the entry smear because of the lack of endocervical cells. This was not the case; cohort B had no more histologic high-grade disease than cohort $\mathrm{A}$ (standardized incidence ratio for cohort B compared with cohort A $0.89,95 \%$

Table 1: Clinical guidelines for treatment when transformation zone cells are not present in sample

Guidelines, by location or organization

Alberta $^{29}$

British Columbia ${ }^{30}$

Ontario $^{31}$

Manitoba $^{32}$

Newfoundland and Labrador ${ }^{33}$

Nova Scotia ${ }^{34}$

New Brunswick, Prince Edward

Island, Saskatchewan,

Northwest Territories, Nunavut,

Yukon, Quebec

Society of Obstetricians and

Gynaecologists of Canada ${ }^{35}$

United Kingdom ${ }^{36}$

Australia ${ }^{37}$

American Cancer Society

\section{Recommendation}

Current guidelines state, "The ideal sample has both ectocervical and transformation zone cells in adequate numbers to detect abnormalities." However, the guidelines also note that "the presence of endocervical cells is not necessary for the sample to be 'satisfactory for evaluation' as per Bethesda 2001. An adequate number of squamous epithelial cells is required." No explicit recommendations are given on what to do if endocervical cells are not present.

Current guidelines state, "The presence of endocervical cells, metaplastic cells and squamous cells suggest a high probability that the transformation zone has been sampled, which is necessary for a cervical smear to be considered optimal." The guidelines add that the test is considered unsatisfactory if "[the] sample consists mainly of endocervical glandular cells (sample mainly from the endocervical canal and not representative of the transformation zone)." It should be noted that the absence of transformation zone cells is not given as a reason for an unsatisfactory test, and that no explicit recommendations are given for what to do when endocervical cells are absent.

Guidelines do not mention the presence or absence of endocervical cells.

Guidelines are summarized in the Pap test learning module as follows: "The presence of squamous metaplastic cells and/or dysplastic cells and/or endocervical cells is generally regarded as evidence of adequate sampling of the transformation zone. If the components of the transformation zone are absent in a satisfactory Pap test, you may not need to repeat the Pap test if the individual has had routine Negative Pap tests. The decision to repeat the Pap test is based on the cytology diagnosis and not the presence or absence of transformation zone cells." Guidelines do not mention the presence or absence of endocervical cells.

Current guidelines state, "The presence of squamous cells, endocervical cells and/or metaplastic cells on a smear suggests a high probability that the transformation zone has been sampled, which is necessary for a cervical smear to be considered optimal." The guidelines continue: "The absence of a transformation zone component should be reported by the laboratory in the specimen adequacy section of the smear report but does not mean a patient requires early repeat [testing]. Attention, however, to regular screening is suggested (Bethesda 2001)."

No guidelines are available.

Current guidelines state, "If the number of cells from the transformation zone was insufficient, the pathologist can still give a result with reservation, but this situation is insufficient for the patient to be recalled before she is due for her next Pap smear."

The guidelines published by National Health Service (Wales) advise that "in some cases, a negative result may be accompanied by additional information: 'no evidence of transformation zone sampling.' Such tests do not need to be repeated."

Current guidelines state, "Retrospective cohort studies have shown that women with smears lacking endocervical cells are not more likely to have squamous lesions on follow-up than are women whose smears have endocervical cells."

Current guidelines state, "If endocervical cells/transformation zone elements are absent or if there are partially obscuring factors, an annual repeat may be considered, and selected women may benefit from an earlier repeat test." 
confidence interval [CI] 0.67-1.12). This result suggests that the absence of an endocervical component is not linked to increased rates of subsequent abnormality for both histologic and cytologic outcomes. The author concluded that early repeat testing is unnecessary.

Another key finding in Mitchell's study was that cohorts $\mathrm{B}, \mathrm{C}$ and $\mathrm{D}$ showed less disease than cohort A. This finding raises a new question: Does the presence of endocervical cells actually indicate a greater risk of cervical abnormality? Mitchell and Medley suggested in an earlier study ${ }^{17}$ that the transformation zone may be more easily sampled when abnormality is present because of the reduced adhesiveness of cells. A recent blinded, comparative cross-sectional study ${ }^{14}$ showed that cervical smears with a higher number of endocervical cells (> 50 cells) was significantly associated with the presence of at least 10 squamous atypical cells (odds ratio $2.87,95 \%$ CI $1.54-5.35$ ). This finding suggests that there is a positive association between the number of endocervical cells and the number of atypical cells in a smear, and supports the hypothesis that endocervical cells may be more accessible in cervices with abnormalities. The presence of these cells may be a marker in women with a greater risk of cervical abnormality, indicating a higher risk for disease. However, more research is needed to explore this hypothesis.

Although the longitudinal studies described present the strongest evidence available, some limitations do exist with this type of study. Other explanations for their findings are possible. For example, in longitudinal studies with cytologic follow-up, Pap smears without endocervical cells may be less sensitive than those with endocervical cells. Thus, abnormalities may be missed on subsequent Pap tests that do not include an endocervical component. In longitudinal studies with histologic data, only positive cytologic results are usually verified. If Pap tests without endocervical cells are less sensitive, these test results are less likely to be subject to histologic verification. As a consequence, verification bias may occur, giving the impression that such women are at low risk for cervical abnormalities when they are actually not. Studies with shorter follow-up periods are more prone to this bias. More research is required to address these concerns.

\section{Should women whose Pap smears lack endocervical cells be retested?}

Studies using multiple methodologies have at tempted to determine the role of endocervical cells in Pap tests in the detection of cervical cancer, but the conclusions of these studies have often been contradictory. According to the crite- ria of the Canadian Task Force on Preventive Health Care ${ }^{39}$ contradictory evidence receives a $\mathrm{C}$ grade, meaning that no recommendation can be made. However, the majority of recent, rigorous and validated studies support the view that the presence of endocervical cells is not necessary for a Pap smear result to be valid and may possibly be a risk factor for cervical abnormality. As such, this body of research represents fair evidence to recommend avoiding early repeat testing for those women whose Pap smears are negative and do not contain an endocervical component.

\section{Are there differences among Pap smear sampling techniques?}

Efforts have been made to improve the sampling methodology for the collection of adequate Pap smear samples. Over the years, accepted sampling techniques have changed. Studies included in our review used a variety of sampling techniques, such as wooden spatula and cotton swab ${ }^{19,25}$ and ThinPrep Pap tests. ${ }^{23}$ Many of the studies we reviewed did not differentiate among sampling techniques. However, Mitchell and Medley ${ }^{16}$ found that using a combination of cytobrush and spatulae, compared with just using spatulae, improved the probability of having endocervical cells reported in the sample. It is not known, however, whether different sampling techniques affect detection rates of atypia depending on the presence or absence of endocervical cells. Therefore, we suggest that clinicians continue to use the sampling technique recommended by guidelines in their area.

There may be other factors that influence the collection of an adequate sample. For instance, the Alberta guidelines ${ }^{29}$ suggest some conditions for optimal collection, including the stipulation that patients refrain from use of contraceptive creams or jellies, douching, intravaginal medication and sexual intercourse for 24 hours before the test. However, a review of the evidence underlying these recommendations is beyond the scope of this paper. To optimize the collection of a specimen, clinicians should follow the manufacturer's directions.

\section{Gaps in knowledge}

This review is not designed to posit a biological mechanism that might explain the contradictory claims of the studies examined. Future inquiry may seek to validate the hypothesis of Mitchell and Medley ${ }^{17}$ that when atypia is present, endocervical cells slough off the transformation zone more readily, which accounts for their frequent presence in positive samples. Testing other hypotheses that seek to reconcile the con- 
tradictory evidence is also important for a full understanding of the role of endocervical cells in the development of cervical cancer. Various sampling methods were used in the studies examined by this review, but this paper does not address the effectiveness of different sampling techniques.

More studies are needed to determine whether there is a higher incidence of invasive cervical cancer among women whose Pap smears lack endocervical cells. Prospective, longitudinal studies of longer duration, encompassing the onset of atypia to the development of cervical cancer, would also benefit this area of study. A close examination of regional guidelines is also recommended to ensure that the most accurate and upto-date information from rigorous research is being relayed to practitioners.

\section{The case revisited}

Mrs. McTavish returns to review her Pap test results. Her physician assures her that the result is normal and that there will be no change in the scheduling of her screening Pap tests. She wonders about the meaning of the phrase "inadequate number of endocervical cells present" included in the report. The physician explains that there is a zone in the cervix from which most abnormalities arise. There has been some suggestion that, when there is a lack of these endocervical cells on a Pap smear, perhaps this zone was not adequately sampled. However, a balance of research articles shows that a lack of endocervical cells on a Pap test result does not lead to an increased risk of abnormality for someone like Mrs. McTavish. Therefore, Mrs. McTavish can continue with regularly scheduled Pap tests. Local guidelines should be consulted to determine the timing of the next Pap test.

\section{Conclusion}

Based on the strongest evidence available, when a physician is confronted with a Pap smear result lacking endocervical cells, an appropriate course of action would be to schedule the patient for regular testing unless there is suspicion of abnormality, such as abnormal bleeding or other clinical indicators of cervical abnormality. The patient would not be required to undergo an uncomfortable and invasive procedure a second time. Minimizing unnecessary procedures can save the health system considerable expenditures in the form of physician time, testing supplies, laboratory analyses and other costs. It would be helpful for clinicians if provincial and national guidelines were updated to reflect recent re- search in this area. Local guidelines, however, are an excellent resource for best practices in Pap smear techniques.

\section{References}

1. Liu S, Semenciw R, Probert A, et al. Cervical cancer in Canada: changing patterns in incidence and mortality. Int J Gynecol Cancer 2001;11:24-31.

2. Apgar BS, Zoschnick L, Wright TC. The 2001 Bethesda System terminology. Am Fam Physician 2003;68:1992-8.

3. The periodic health examination. Canadian Task Force on the Periodic Health Examination. CMAJ 1979;121:1193-254.

4. Weinstein LC, Buchanan EM, Hillson C, et al. Screening and prevention: cervical cancer. Prim Care 2009;36:559-74.

5. Elias A, Linthorst G, Bekker B, et al. The significance of endocervical cells in the diagnosis of cervical epithelial changes. Acta Cytol 1983;27:225-9.

6. Kivlahan C, Ingram E. Papanicolaou smears without endocervical cells: Are they inadequate? Acta Cytol 1986;30:258-60.

7. Vooijs PG, Elias A, van der Graaf Y, et al. Relationship between the diagnosis of epithelial abnormalities and the composition of cervical smears. Acta Cytol 1985;29:323-8.

8. Kristensen GB, Skyggebjerg KD, Hølund B, et al. Analysis of cervical smears obtained within three years of the diagnosis of invasive cervical cancer. Acta Cytol 1991;35:47-50.

9. Laverty CR, Farnsworth A, Thurloe JK, et al. The importance of the cell sample in cervical cytology: a controlled trial of a new sampling device. Med J Aust 1989;150:432-4, 436.

10. Mauney M, Eide D, Sotham J. Rates of condyloma and dysplasia in papanicolaou smears with and without endocervical cells. Diagn Cytopathol 1990;6:18-21.

11. Woodman CB, Williams D, Yates M, et al. Indicators of effective cytological sampling of the uterine cervix. Lancet 1989;2:88-90.

12. Beeby AR, Wadehra V, Keating PJ, et al. A retrospective analysis of 94 patients with CIN and false negative cervical smears taken at colposcopy. Cytopathology 1993;4:331-7.

13. Robertson JH, Woodend B. Negative cytology preceding cervical cancer: causes and prevention. J Clin Pathol 1993;46:700-2.

14. Ribeiro AA, Santos Sdo C, de Souza e Silva SR, et al. Endocervical component in conventional cervical smears: influence on detection of squamous cytologic abnormalities. Diagn Cytopathol 2007;35:209-12

15. Kwikkel HJ, Quaak MJ, de With C. Predictive value of the abnormal PAP smear: a retrospective analysis of error rates. Eur J Obstet Gynecol Reprod Biol 1986;21:101-12.

16. Mitchell H, Medley G. Longitudinal study of women with negative cervical smears according to endocervical status. Lancet 1991;337:265-7.

17. Mitchell H, Medley G. Influence of endocervical status on the cytologic prediction of cervical intraepithelial neoplasia. Acta Cytol 1992;36:875-80.

18. Mitchell H, Medley G. Cytological reporting of cervical abnormalities according to endocervical status. Br J Cancer 1993;67:585-8.

19. Sidawy MK, Tabbara SO, Silverberg SG. Should we report cervical smears lacking endocervical component as unsatisfactory? Diagn Cytopathol 1992;8:567-70.

20. O'Sullivan JP, A'Hern RP, Chapman PA, et al. A case-control study of true-positive versus false-negative cervical smears in women with cervical intraepithelial neoplasia. Cytopathology 1998;9:155-61

21. Bos AB, van Ballegooijen M, Elske van den Akker-van Marle $\mathrm{M}$, et al. Endocervical status is not predictive of the incidence of cervical cancer in the years after negative smears. Am J Clin Pathol 2001;115:851-5.

22. Mitchell HS. Longitudinal analysis of histologic high-grade disease after negative cervical cytology according to endocervical status. Cancer 2001;93:237-40.

23. Selvaggi SM, Guidos BJ. Endocervical component: Is it a determinant of specimen adequacy? Diagn Cytopathol 2002;26:53-5.

24. Siebers AG, de Leew H, Verbeek AL, et al. Prevalence of squamous abnormalities in women with a recent smear without endocervical cells is lower as compared to women with smears with endocervical cells. Cytopathology 2003;14:58-65.

25. Pajtler M, Audy-Jurković S. Pap smear adequacy — is the assessing criterion including endocervical cells really valid? Coll Antropol 2002;26:565-70.

26. Tacken MA, Braspenning JC, Mulder J, et al. Loss to follow-up of cervical smears without endocervical columnar cells is not disturbing. Eur J Gynaecol Oncol 2006;27:42-6.

27. Giorgi Rossi P, Baiocchi D, Ciatto S. Endocervical cell Italian working group of cervical cancer screening group. Acta Cytol 2010;54:265-71. 


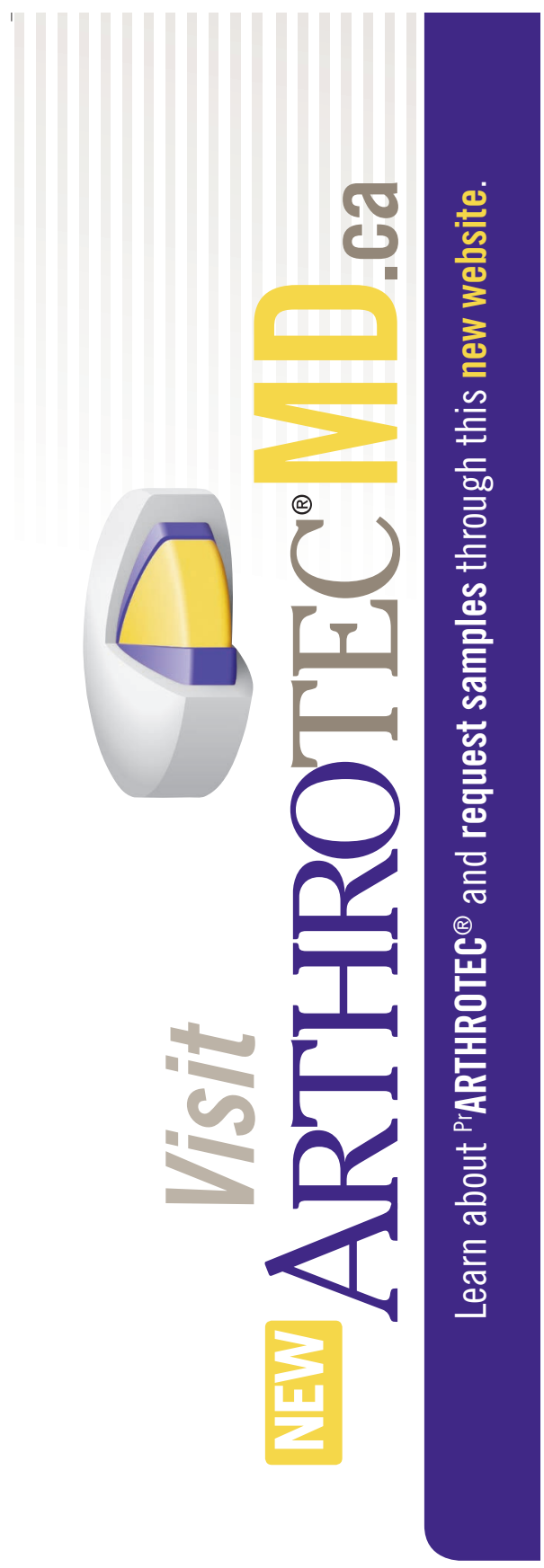

\section{REVIEW}

28. Mintzer M, Curtis P, Resnick JC, et al. The effect of the quality of Papanicolaou smears on the detection of cytologic abnormalities. Cancer cytopathology. 1999; 87:113-7.

29. Guideline for screening for cervical cancer. Edmonton (AB): Toward Optimal Practice Program; 2000. Available: www.top albertadoctors.org/informed practice/clinical practice guidelines /complete\%20set/Cervical\%20Cancer/cervical_cancer_guideline .pdf (accessed 2010 July 14)

30. Screening for cancer of the cervix: an office manual for health professionals. Vancouver (BC): Cervical Cancer Screening Program, BC Cancer Agency; 2010. Available: www.bccancer.bc.ca /NR/rdonlyres/BB10EE87-95AB-43F5-994C-

7D8DBD969424/47976/CCSPOfficeManualWebFinal2011.pdf (accessed 2011 Feb. 22).

31. Ontario cervical cancer screening practice guidelines. Toronto (ON): Ontario Cervical Screening Program, Cancer Care Ontario; 2007. Available: www.cancercare.on.ca/common /pages/UserFile.aspx?fileId=13104 (accessed 2010 July 14).

32. Pap test results in Pap test learning module for health care providers. Winnipeg (MB): Manitoba Cervical Cancer Screening Program, Cancer Care Manitoba; 2009. Available: www.cancer care.mb.ca/resource/File/MCCSP/HealthCareProfessional/PTLM _Chapter_10.pdf (accessed 2010 July 14).

33. Cervical Screening Initiatives Program 2008: clinical management guidelines. Stephenville (NL): Western Health; 2008. Available: http://westernhealth.nl.ca/uploads/PDFs/Clinical_Mg _Guidelines_2008.pdf (accessed 2010 July 14).

34. Screening for cancer of the cervix: an office manual for health professionals. Halifax (NS): Cervical Cancer Prevention Program, Cancer Care Nova Scotia; 2009. Available: www.cancercare.ns .ca/site-cc/media/cancercare/CCPPManual09WEB.pdf (accessed 2010 July 14).

35. Steban M. Clinical manifestation and diagnosis of HPV-related disease In: Canadian consensus guidelines on human papillomavirus. J Obstet Gynaecol Can 2007;29(Suppl 3):S11-4.

36. Cervical Screening Wales quality manual. Section 2 - core reference section. National Health Service London (UK): 2009 Available: www.screeningservices.org.uk/csw/prof/quality/core reference_v1.0_rev3.pdf (accessed 2010 July 15).

37. Screening to prevent cervical cancer: guidelines for the management of asymptomatic women with screen detected abnormalities. Canberra (Australia): National Health and Medica Research Council; 2006. Available: www.nhmrc.gov.au/_files _nhmrc/file/publications/synopses/wh39.pdf

38. Saslow D, Runowicz CD, Solomon D, et al. American Cance Society Guideline for the early detection of cervical neoplasia and cancer. CA Cancer J Clin 2002;52:342-62.

39. Canadian Task Force on Preventive Health Care. New grade for recommendations from the Canadian Task Force on Preventive Health Care. CMAJ 2003;169:207-8

Affiliation: From the Department of Family Medicine, University of Calgary, Calgary, Alta.

Contributors: Both of the authors contributed to the planning and design of the article, the review of the literature, and the drafting and revision of the manuscript. Both of them approved the final version of the manuscript submitted for publication.

Acknowledgements: The authors thank Neil Drummond, Tyler Williamson, Behnaz Somji and members of the Southern Alberta Primary Care Research Network for their help in the development of this paper.

An NSAID with a mucosal protective agent, ${ }^{\text {PrARTHROTEC }}{ }^{\circledR}$ (50 \& $75 \mathrm{mg}$ diclofenac sodium and misoprostol tablets) has contraindications as well as warnings and precautions of use.

Please consult the Prescribing Information which is available on the ARTHROTECMD.ca website, or the Product Monograph which is available upon request.

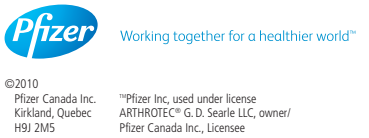

